\title{
Crescendo como um Xikrin: uma análise da infância e do desenvolvimento infantil entre os Kayapó-Xikrin do Bacajá ${ }^{1}$
}

\author{
Clarice Cohn \\ Mestre em Antropologia Social - USP
}

\begin{abstract}
RESUMO: Este artigo busca entender o processo de desenvolvimento infantil entre os Xikrin através de sua própria concepção de criança e do crescimento, além de uma análise que busca focar o modo como as crianças intervêm ativamente nesse processo. Assim, o artigo filia-se a uma nova ênfase da antropologia contemporânea, aquela que recupera os estudos sobre a infância em outras sociedades a partir de concepções de Pessoa e da participação ativa da criança em sua própria inserção na vida social, recusando a visão da socialização como meio de incutir em "imaturos", que imitam e miniaturizam a vida adulta, valores e comportamentos socialmente aceitos.
\end{abstract}

PALAVRAS-CHAVE: antropologia da infância, socialização, aprendizado, transmissão de conhecimentos.

\section{Introdução}

Nesse artigo, propõe-se revisitar os Xikrin, subgrupo Kayapó, de língua Jê, habitante do sudoeste do Pará, para discutir o modo como eles concebem a infância e o desenvolvimento infantil, assim como o aprendizado. Nessa nova abordagem, recorremos às análises que efetuam uma revisão do modo como a antropologia tratava da infância nas sociedades que estudava. A etnografia sobre as concepções xikrin e da condição de participação das 
crianças é apresentada de modo a demonstrar como, também para eles, as crianças devem ser vistas e entendidas em sua especificidade, e não como adultos em miniatura.

As produções recentes na antropologia que se voltam ao aprendizado e à infância têm ressaltado a importância de se atentar para a participação ativa das crianças na vida social e na construção de sentidos a partir de sua vivência e interação. Christina Toren $(1990,1999)$ propõe que a antropologia deva se voltar ao estudo de uma "microhistória", em que o entendimento sobre o mundo social é construído por cada indivíduo ao longo da vida a partir da intersubjetividade; a ênfase na construção desse entendimento pressupõe que ambas as partes, e não apenas o "socializador", sejam tidos como agentes, em uma recusa da passividade da recepção dos valores e atributos sociais, substituída aqui pela construção de significados e sentido na interação.

Reconhecendo a criança como um agente que constrói suas relações e atribui sentidos, a antropologia revê a análise do processo de socialização, deixando de pensar a criança como tendo incutido valores e comportamentos e se constituindo em pessoa plena rumo a um produto social já conhecido de antemão (Schildkrout, 1978), ou como mera reprodutora de um mundo adulto, mas sim como um ator social ativo e produtor de cultura (Caputo, 1995; Pelissier, 1991). Possibilita-se assim que o estudo da infância nessas sociedades enfoque um mundo relativamente autônomo, que tem validade por si, nas experiências e na vivência das crianças, e em suas formulações sobre o mundo em que vive, vendo-a como um agente, e não como um sujeito incompleto, ou um adulto em miniatura que treina a vida adulta, ou, como sugere Schaden (1945: 271), aprendendo por imitação, definida como um " "instinto social' que faz com que a criança, antes de chegar à puberdade, 'aprenda brincando' todas essas habilidades”, tornando-se gradativamente um "ser social pleno"2.

Os estudos sobre a noção de pessoa vêm possibilitar que se apreenda o modo como cada sociedade concebe a infância e também o "ser pleno" em que ela se desenvolve, permitindo que se veja do interior de cada 
sociedade analisada o modo como este é definido, e, portanto, não o estabelecendo como uma construção do pesquisador. Eles permitem entender qual a definição social de humanidade, quais os processos necessários para que se adquira o atributo de ser humano, como a sociedade intervém nesses processos, que não são tidos como finitos, mas contínuos, e como o conjunto dessas variáveis atua para definir a infância e, em alguns casos, os estágios que a conforma (Howell, 1988; Overing, 1988).

Por último, podemos evocar trabalhos que demonstram a construção de relações sociais, como o de Peter Gow (1991), sobre os Piro amazônicos, ou de Strathern (1988), sobre a constituição das relações de gênero e da pessoa na Melanésia. Gow (: 158-9) mostra que as relações de parentesco, extremamente importantes para os Piro, são definidas a partir de dois idiomas, um voltado à corporalidade e à formação do corpo dos filhos pelos pais, a que ele chama "fisiológico", e outro, que sugere ser mais importante, voltado ao cuidado e à alimentação, à comensalidade, que constrói a relação e a memória que define o parentesco. Ele demonstra, ainda, que o segundo idioma de parentesco pode substituir o primeiro, como é o caso da adoção. Por fim, o uso de termos de parentesco, ligados à instituição e efetivação das relações sociais, não é ensinado às crianças, mas, ao contrário, elas os selecionam, e os adultos respeitam sua escolha como indicativa da relação estabelecida pela criança (: 161). Portanto, para ser considerada real pelos Piro, uma relação tem de ser efetivada, não bastando para isso categorias sociais e relações estabelecidas e potencialmente herdadas das gerações ascendentes, mas, ao contrário, necessitando-se para isso das experiências e da interação (: 194).

Strathern já havia estabelecido um modelo explicativo do que denomina a socialidade melanésia, no qual toma a ativação das relações sociais como determinantes da pessoa, seja como agente seja como referência e motivação às ações dos outros. A pessoa seria concebida pelos melanésios, portanto, como construída pelas relações que a produziram, como um "microcosmo social" (1988: 13). Interessada na definição do gênero, a autora sugere que ele não é dado, mas construído - não se estabelece pela natureza 
ou pela aparência, mas na eficácia da ação a partir das capacidades que são próprias a cada gênero, o que implica a interação e determina a relação com outros como caracterizada pelo gênero (Strathern, 1988: $123,128)$. A pessoa melanésia, composta que é de relações, revela-se no contexto mesmo de suas relações (: 274); e o que importa é sua habilidade em ativar relações (: 275). Portanto, a autora conclui:

a supressão de alternativas múltiplas em benefício de uma torna as relações visíveis pela capacidade da pessoa de as ativar (...) as relações sempre estiveram aí; o que dá ao evento seu caráter único é quão bem ou de que modo uma relação é feita "aparecer" naquela ocasião. (: 277-8, tradução minha) $)^{3}$.

Vejamos então como os Xikrin concebem a infância e seu desenvolvimento - físico e/ou intelectual - e como se dá a participação dessas crianças na vida cotidiana e nos rituais, para que possamos discutir como eles concebem a atuação das crianças na construção de suas relações e de significados para o que vivem, e como elas levam a cabo essas tarefas.

\section{A infância xikrin e o aprendizado}

Os Xikrin dizem que as crianças já nascem compostas por corpo (in) e karon, este último glosado pelos antropólogos como alma ou duplo. $\mathrm{O}$ karon, assim, parece se constituir durante a gestação, embora sua origem não seja enfatizada ou problematizada pelos Xikrin. O corpo do recémnascido é mole (rerekre) e endurece com o tempo. Esse processo é relacionado à pele $(k a)$, ela mesma tornando-se dura (kà tox). A importância da pele para a constituição da pessoa entre os Kayapó foi enfatizada por diversos autores, e Terence Turner $(1981,1995)$ argumenta que a pele funciona como um intermediário entre a pessoa social e seu interior "psicosociológico". Nela deve ser aplicada a pintura corporal, uma "pele social" que, expressando valores e significados, realiza a conversão dos poderes internos do indivíduo, naturais e não-socializados, à sociedade, dando-lhes 
assim forma social. Giannini (1991a: 151,153), ao analisar os elementos constitutivos da pessoa xikrin (sangue, órgãos internos, ossos, karon e kadjuo, que glosa como energia vital ${ }^{4}$ ), argumenta que os Xikrin enfatizam os perigos das doenças de pele porque estas seriam um indício da interrelação dos elementos internos da pessoa, e que, portanto, um estado anormal da pele indicaria uma desintegração interna da pessoa. Seus elementos internos, portanto, estão em fraca relação quando de uma doença, mas também nos recém-nascidos; assim o conceito de duro e mole, relativo a eles, diz respeito à relação entre os elementos internos e constitutivos da criança, tendo como índice visível a "pele mole".

Tendo ainda a pele mole, e, portanto, seus elementos constitutivos pouco integrados, o recém-nascido corre grandes riscos de perder seu karon. Essa uma preocupação corrente entre os responsáveis pelo bem-estar de uma criança. O karon de qualquer pessoa pode se ausentar do corpo, como o faz durante o sono, propiciando assim os sonhos, mas deve sempre retornar; quando não retorna, leva à morte. Os recém-nascidos, enquanto não têm a pele dura, são comparativamente mais vulneráveis à perda de seu karon, especialmente quando zangados; por isso, não se permite que chorem muito, o que sinalizaria o risco da perda irremediável do karon ${ }^{5}$. Em menor grau, essa preocupação se estende a todas as crianças, e dizse por isso que os adultos, principalmente os pais, não devem brigar com elas, pois elas se afastam chorando e bravas, ficando assim vulneráveis a que um parente morto leve seu karon. A análise de Giannini nos ajuda a entender porque a pele mole indica uma maior vulnerabilidade de perda de karon - não porque seja um envoltório capaz de guardá-lo, mas porque é índice da formação de todos os aspectos do indivíduo.

O corpo da criança precisa, portanto, se desenvolver: estabelecer uma integração entre seus elementos internos, o que é tornado visível pela pele "dura". Os Xikrin, ao contrário, não afirmam que o karon deve também se desenvolver; no entanto, o desenvolvimento e crescimento de uma criança no mundo dos mortos, assim como sua necessidade de, como em vida, ser criada por um adulto, parece indicar que ele se desenvolve, já 
que os mortos, tendo perdido o corpo, são karon ${ }^{6}$. No entanto, não são apenas os elementos internos da criança que devem se desenvolver, mas também seus órgãos sensoriais, especialmente os olhos e os ouvidos, que lhe possibilitarão aprender e assim, além de obter conhecimentos, agir apropriadamente.

Para os Xikrin, saber, conhecer, aprender, entender e compreender estão todos inseridos em duas capacidades, a de ver e ouvir. Quando afirma saber ou ter aprendido algo, um Xikrin pode optar entre dizer arym ba kuma, o que poderíamos traduzir como “eu já ouvi”, e arym ba omunh7, que poderia ser traduzido por "eu já vi”. Quando, correspondentemente, se refere a ter ensinado algo a alguém, dirá ba kum akre (eu mostrei a ele/ a) ou ba kum iaren (eu contei a ele/a $)^{8}$. Do mesmo modo, a capacidade de aprender e entender é correlacionada às capacidades sensoriais de ver e ouvir, e as crianças devem desenvolver esses órgãos. Isso faz parte do crescimento natural da criança e, embora seja uma característica individual, algumas crianças se diferenciam das outras por seu desenvolvimento mais rápido. Mas pode, também, ser induzido ou impedido pela ingestão ou contato com algumas substâncias.

Uma criança não deve comer a cabeça do peixe, sob risco de não se tornar capaz de aprender, e essa comida é reservada aos velhos, aqueles que já sabem e já aprenderam. Os rapazes solteiros (menoronyre) reunidos no ngà (a casa central onde os homens se encontram à noite ${ }^{9}$ ) devem também respeitar diversas restrições alimentares voltadas ao desenvolvimento de seu olho, nesse caso explicitamente relacionado com sua habilidade de caçador. $\mathrm{O}$ caso de um velho que é tido como pouco conhecedor, e que, apesar da idade, não se ressalta nas performances rituais e na oratória, parece aos Xikrin paradoxal. O interessante é que a explicação que recebi para essa situação é a de que ele deve ter comido algo ruim (moja punu) quando jovem, e se tornado portanto incapaz de compreender e aprender. Um caso observado em campo possibilita ilustrar o modo como a ingestão de alimentos pode impedir o aprendizado, mas como ele pode ser restaurado por meio de outras substâncias. 
Uma menina de cerca de dois anos falava enrolado e com pouca freqüência, o que preocupava seus pais e avós. Comparando-a com uma prima (MZD) de mesma idade, eles sempre notavam sua pouca fluência verbal. O diagnóstico para seu caso, feito pelo avô (MF), foi a ingestão de um fruto nos arredores da roça da mãe, que era repreendida por isso, tido como um descuido: deveria estar atenta ao que a menina fazia. $\mathrm{O}$ avô, então, preparou um remédio para a criança, que consistia em passar uma pena de pássaro (que não consegui identificar) em sua língua e ouvido, para que ela pudesse aprender a falar bem: preocupava-se em "desenrolar" sua língua (a menina falava, dizia seu avô, de maneira que ninguém entendia), mas também em lhe curar o ouvido, para poder entender bem, e assim falar propriamente.

A ligação que os Xikrin fazem entre o ver e o ouvir e a capacidade de aprender não deve, no entanto, ser entendida por demais literalmente, associando o ouvido com narrativas e $\mathrm{o}$ aprendizado de mitos, por exemplo, e os olhos com as atividades produtivas e a confecção de cultura material. Na realidade, em seu uso comum, mari (ouvir) parece englobar omunh (ver), e se esse é utilizado apenas nos casos em que alguém aprende vendo (como fazer um cocar), aquele pode ser utilizado para todas as situações de aprendizado. Isso pode ser entendido a partir de uma explicação que recebi de um informante, a de que o olhar sozinho não basta para o aprendizado, e deve ser acompanhado da compreensão, essa possibilitada pelo ouvido. Adquire sentido, assim, uma fala comum aos homens quando tratam de seus conhecimentos, a de que já viu (omunh) fazendo mas não sabe (mari) fazer: eles parecem fazer aqui referência ao fato de que viu fazendo mas não se dedicou de fato a tentar aprender, o que poderíamos traduzir de um modo que me parece fiel como "não parou para prestar atenção". Além dos órgãos sensoriais que lhe capacitam a aprender e compreender, a criança deve também desenvolver ("fortalecer") o coração (angoro), no qual os conhecimentos adquiridos são armazenados.

O momento em que a criança está pronta para aprender é indicado por ela mesma, quando, como me disse uma vez um homem, começar a "sentar 
ao lado [de quem sabe] para ouvir". Do mesmo modo, o que elas vão aprender não depende apenas de suas relações sociais, mas também de sua iniciativa, que toma a forma de um "pedido" (kukiere) para que alguém que domine esse conhecimento lhe ensine. Esse pedido pode ser feito para pessoas com quem não se tem uma ligação de parentesco, embora deva-se sempre respeitar as restrições de comunicação envolvidas; por isso, um jovem me disse que havia pedido a um velho a quem chama de sogro que lhe ensinasse alguns remédios do mato, mas por intermédio de um de seus netos, que intermedia não apenas o pedido, mas também a situação de aprendizado, acompanhando os dois homens na floresta. Assim o interesse e a motivação para o aprendizado são individuais, e o repertório de conhecimentos adquiridos é dado pela iniciativa, e não pela posição social.

Há porém momentos de aprendizado coletivo, e conhecimentos que se considera apropriados para cada categoria de idade. $\mathrm{O}$ aprendizado coletivo ocorre principalmente quando se realiza rituais, em seus preparativos, quando jovens e velhos se reúnem para ensaiar os cantos e os passos do ritual. No passado, quando os jovens menoronyre permaneciam mais tempo na casa dos homens, diversas situações eram criadas, permitindo um aprendizado pela coletividade dos jovens; por exemplo, eles às vezes eram incumbidos de trazer material para a confecção de adornos, que os velhos faziam em sua companhia. Assim também, era comum ouvir como resposta à pergunta sobre quem sabia fazer algo uma categoria de idade. Sugiro, porém, que isso deva ser entendido menos como indicativo de momentos de aprendizado específico, mas de momentos em que é possível demonstrar determinados conhecimentos. Ou seja, pela negativa: se algumas coisas todos devem saber, algumas categorias de idade não as podem fazer. Portanto, indica-se, nessas respostas, não quando se deve adquirir este ou aquele conhecimento, mas a partir de quando se pode começar a explicitá-lo e praticá-lo. Isso pode ser ilustrado com a confecção do cocar krokroti, o maior deles, e de uso exclusivamente ritual. Dele se diz que só os velhos o sabem fazer; e, de fato, só os velhos o fazem, já que, se um jovem se arriscasse a confeccioná-lo, ficaria com os cabelos 
brancos - ou seja, envelheceria. Não se estabelece aqui, portanto, quando os homens aprendem a fabricar um krokoti, mas quando podem começar a efetivar esse aprendizado - sob o risco de, pulando uma etapa nas prerrogativas de explicitação do conhecimento, pular também uma etapa no ciclo de vida ${ }^{10}$.

Para os Xikrin, as crianças não apenas crescem fisicamente, mas tornamse também mais envolvidas com a vida social, socializam-se. Para isso, têm de desenvolver a habilidade de compreender o que é ou não socialmente aceitável. As crianças xikrin não têm, até uma certa idade, responsabilidades. Isso quer dizer não apenas que elas não são requisitadas para realizar tarefas consideradas perigosas ou penosas para sua idade, mas também que não se espera que elas saibam como se comportar. Delas, se comenta: "ela não sabe ainda", mari ket rã'ã. Mas o fato de não saber ainda é considerado razão suficiente para não culpar a criança por seus atos. E os Xikrin dizem que uma criança nada sabe porque ainda é criança, mas tudo sabe porque tudo vê e ouve. Já sabemos porque as crianças nada sabem (não se espera que elas compreendam antes de amadurecerem os órgãos que lhes possibilitem a compreensão), mas resta saber porque se afirma, simultaneamente, que elas tudo sabem. Como eles mesmo dizem, é porque elas tudo vêem e ouvem, e é a sua condição de participação em tudo o que acontece que lhes permite ir gradativamente construindo um sentido para o que vêem e ouvem. Assim o que pode nos soar contraditório, a afirmação simultânea pelos Xikrin de que as crianças tudo e nada sabem, deve ser entendido lembrando-se de que elas devem aprender a construir um sentido ao que vêem e ouvem, mas que lhes está aberta a possibilidade de testemunhar toda a vida social e ritual xikrin. É esse jogo entre poder observar e aprender que se tenta demonstrar no que segue.

\section{A participação da criança na vida social}

A vida da criança difere qualitativamente da dos adultos. Assim, se pouco lhe é proibido ${ }^{11}$, não se espera que elas se comportem como pequenos 
adultos. De fato, poderíamos pensar em suas atividades pela negativa: elas não participam de modo decisivo das atividades produtivas, não andam sozinhas longas distâncias, não constituem família, não abraçam as responsabilidades dos adultos, não participam da política e das decisões que concernem o coletivo. Porém, como sugere Schildkrout (1978), é analiticamente mais rentável buscar o que caracteriza a infância e sua experiência nas diversas sociedades do que tentar mensurá-la, quantitativamente, em relação à experiência dos adultos. Assim, no que segue, tento dar uma mostra do que seja essa experiência das crianças xikrin, na vida cotidiana assim como nos rituais ${ }^{12}$.

\section{O cotidiano das crianças}

Em seu cotidiano, as crianças se diferenciam, assim como os adultos, em grupos formados a partir dos critérios de idade e gênero. Os meninos têm maior liberdade de movimentação do que as meninas, e desde cedo se reúnem para realizar pequenas caçadas nos arredores da aldeia ou para fazer expedições nas capoeiras ou nas roças próximas ${ }^{13}$. Esses seriam, aliás, casos em que se poderia interpretar suas atividades como uma imitação em miniatura do mundo adulto - caça de pequenos animais não comestíveis com armas "de brinquedo", ou ida às roças em busca de ninhos de marimbondo para derrubar, como num ensaio do que terão de fazer, mais tarde, durante a iniciação, e que os adultos fazem com frequiência ${ }^{14}$. No entanto, quando os meninos voltam para a aldeia com frutos que eles coletaram em suas expedições, eles os oferecem a suas irmãs, reais ou classificatórias, assim como os homens adultos me reportaram fazer quando, nessas mesmas ocasiões, caçavam passarinhos. Nesses casos, os passarinhos seriam preparados por suas irmãs, que lhes levariam para comer no $a t u k^{15}$. A relevância dessa particularidade será retomada na conclusão deste artigo.

Das meninas, por sua vez, espera-se que elas permaneçam próximas de suas casas, prontas para auxiliar suas parentas mais velhas, especialmente 
no cuidado de crianças menores. De fato, uma das reprimendas das mães às meninas quando elas ficam brincando no pátio e não estão disponíveis para cuidar dos irmãos é "você é menino?", “djãm abê my?". Isso não as impede, porém, de realizar algumas atividades por iniciativa própria, como se reunir para brincar de bonecas, transformando abóboras, olhos de cacho de banana ou qualquer outro objeto em bebês, ou os modelando em argila, e os pintando cuidadosamente com motivos de pintura corporal característicos de bebês de colo, ou ainda para se pintar umas às outras, como na reunião coletiva de pintura das mulheres. Aqui também, no entanto, não devemos entender sua atividade como mera imitação do que os adultos fazem. Assim, se elas se pintam umas às outras, o fazem com carvão (e não com jenipapo, que marca o corpo por dias, e que, como argumentei mais longamente em outro trabalho [Cohn, 2000: 160-4], informando sobre a situação social da pessoa, deve ser realizado de modo apropriado; o carvão, por sua vez, é facilmente lavável), e com uma maior liberdade de combinação de motivos do que têm as mulheres.

No círculo da aldeia, as crianças, independente do sexo, têm maior mobilidade que os adultos, entrando nas casas e passeando pelo pátio, os meninos ocupando mesmo o ngà durante o dia, quando esse se encontra vazio. Desse modo, como já havia notado Vidal (1977: 105), elas atuam como mensageiras entre as casas, levando e trazendo recados e presentes, o que lhes permite "desenvolver muito cedo um conhecimento da rede de relações sociais em que se encontra[m] inserid[as]". Porém, isso não significa que elas estejam livres de restrições em sua relação com as outras pessoas, mas que suas restrições diferem qualitativamente (e, de novo, não quantitativamente) das dos adultos.

As crianças podem atuar como mensageiras e canal de ligação entre as casas por não terem de agir de acordo com o pia'am, ou distância social/respeito, que pauta as relações entre os adultos, o que foi descrito detalhadamente por Turner $(1966,1979)$. Isso não significa que as crianças sejam desprovidas de pia'am; na realidade, elas o têm, e muito. Mas o pia'am que elas sentem e demonstram é de outra natureza do 
dos adultos: se no primeiro caso volta-se a qualquer pessoa não familiar de mais idade que ela própria, como "vergonha", no segundo o pia'am tem origem nas relações de afinidade, e impede a comunicação direta de categorias de pessoas.

As crianças têm muita vergonha quando em companhia de adultos: falam pouco e ficam de cabeça baixa (assim como os jovens, que não olham de frente para os mais velhos). Os momentos em que não sentem - e demonstram - vergonha são basicamente aqueles em que estão rodeadas por pessoas que lhes são familiares (e, mesmo assim, o terão se lhes for perguntado algo que exija uma resposta direta) ou quando estão reunidos em grupo, atuando, assim, como um coletivo. Assim, se o pia'am infantil é, sem dúvida, vergonha e respeito pelos mais velhos, ele é menos marcadamente devido à distância social, já que ela passa a ser mais importante quando se estabelece relações de afinidade.

\section{A participação das crianças nos rituais}

Assim como no cotidiano, as crianças participam dos rituais de modo diferente que os adultos. De fato, ao contrário desses, que participam como um coletivo em todos os rituais, embora possam ter individualmente papéis específicos, as crianças só participam deles quando têm um papel ritual ${ }^{16}$; do contrário, apenas observam. Esses papéis rituais são prerrogativas transmitidas por uma categoria de parentesco, os ngêt (MB, MF, FF) para um menino, ou as kwatui (FZ, FM, MM) para uma menina. São essas pessoas que vão lhes transmitir os nomes, e, em alguns casos, as prerrogativas que possuam de uma participação especial em um ritual ou de uso de adornos.

Se os nomes são transmitidos já ao recém-nascido ${ }^{17}$, a transmissão das prerrogativas rituais pode acontecer em qualquer momento da infância, e é acompanhada de um aprendizado durante o ritual: a criança a quem é transmitida a prerrogativa participa do ritual ao lado de quem o transmitiu, não só aprendendo seu papel, como explicitando-o aos outros. Em uma 
sequiência ideal, ou seja, quando a transmissão é efetivada quando a criança é ainda um bebê, ela é levada no colo por seu/sua nominador(a), para em um ritual subseqüente ir de mãos dadas com ele/a, acompanhá-los então sem necessidade de ser levada, até um dia, com a morte do nominador/a, ir sozinha. Tendo sua prerrogativa confirmada ritualmente, poderão um dia transmiti-la (Lea, 1986: 134, 272).

Mesmo quando não participam ativamente do ritual, as crianças estão sempre presentes, observando seus preparativos e todos os acontecimentos que lhes chamem a atenção. À noite, porém, quando, nos rituais mereremex, os participantes dançam como um coletivo (e não em grupos como o fazem durante o dia), os espíritos dos mortos (mekaron) são ditos retornar à aldeia para assistir à performance dos vivos. $\mathrm{O}$ contato próximo com os mortos é perigoso, e as famílias abandonam suas casas nas noites de ritual, indo acampar no pátio e deixando as casas para os mekaron, que as ocupam durante essa noite. Assim, essas famílias ${ }^{18}$ permanecem em uma posição que lhes permite alternar períodos de sono e de observação do ritual, e as crianças, protegidas dos mortos, podem então assistir ao ritual.

É interessante notar uma particularidade da nominação e da transmissão de prerrogativas entre os Xikrin. Entre os Timbira, por exemplo, os nomes são transmitidos em conjunto para uma só pessoa, e a eles se liga o pertencimento às metades rituais, de tal modo que nominador e nominado compartilham uma personalidade social, e se diferenciam apenas pelo corpo e as relações sociais voltadas à sua construção e manutenção da saúde (Melatti, 1976). Ao contrário, entre os Xikrin (e entre os Kayapó de modo geral, como a pesquisa de Lea [1986: 186-90] entre os KayapóMekranoti demonstra), um conjunto de nomes pode ser repartido e transmitido para pessoas diversas e não há ligações diretas entre um nome e uma prerrogativa ritual ${ }^{19}$. Assim, se o nominado e o nominador são, para os Timbira, "quase a mesma pessoa”, a nominação e a transmissão de prerrogativas entre os Xikrin conformam mais nitidamente identidades sociais distintas. 
Clarice Cohn. Crescendo como um Xikrin

\section{A comunicação oral das crianças}

A oralidade é bastante enfatizada entre os Kayapó, e um homem deve se tornar cada vez mais fluente nas falas formais que caracterizam os discursos realizados no ngà. Quando jovem e recém-inserido na sociedade masculina que se reúne no centro da aldeia, ele deve apenas ouvir respeitosamente os mais velhos, que narram a história do grupo, caças e mitos e fazem exortações sobre o modo de ser xikrin e como se espera que os jovens se comportem. Quando se prepara um ritual, ele deve ouvir também as falas formais que lhe dão início, os bendjire. Todos esses gêneros de oralidade são prerrogativas dos mais velhos, e um homem vai adquirindo espaço para realizá-los de acordo com a categoria de idade em que se insere, a partir do momento em que é considerado "pai de muitos filhos", mekratum ${ }^{20}$. O mesmo pode ser visto acontecendo com as mulheres, que têm no choro ritual uma modalidade de expressão oral pública (Lea, 1986), e que, correspondentemente, deve ser feito pelas mulheres mais velhas (a partir do momento em que são mães de muitos filhos).

Seeger (1980) demonstrou que a ênfase na oralidade como um atributo masculino está ligada entre os Suyá ao uso do batoque labial entre os homens, assim como a habilidade de ouvir bem, que se volta à capacidade de aprender e compreender e de agir de modo socialmente apropriado, deve ser enfatizada para ambos os sexos, que usam o adorno auricular. Esse mesmo arranjo ocorre entre os Xikrin, e penso que a interpretação que Seeger faz da relação entre os ornamentos e a socialização, com algumas diferenças relativas às especificidades dos casos (Cohn, 2000:141-4), pode ser estendida a eles.

Desse modo, os Suyá forneceriam um modelo em que se apresenta mais agudamente uma estrutura também presente entre os Kayapó. Entre aqueles, a perfuração dos lábios e ouvidos coincide no tempo com a ênfase no órgão das faculdades socialmente valorizadas - a audição para ambos os sexos, que permite a ação socialmente correta, e a oratória e o canto para os homens -, já que realizadas mais tarde no ciclo de vida. Em 
contrapartida, a visão ganha entre os Suyá um sinal negativo, ligando-se ao a-social. Nos Xikrin, a realização da capacidade plena de fala e audição é dissociada do momento em que se marcam os órgãos correspondentes, já que batoques labiais e adornos auriculares são inseridos no bebê, e esses últimos retirados quando a criança começa a andar; para eles ainda, a faculdade da visão não é negativa, mas, ao contrário, ganha importância para o aprendizado e a inserção social. No entanto, uma importância minorada, e que pode, como argumentei, ser suplantada pela audição - o que, ao menos, não basta para o aprendizado, e deve vir acompanhada da capacidade de compreender e aprender.

Assim, vejamos como os Xikrin adquirem o que se chama correntemente de competência lingüística e competência pragmática (Schieffelin \& Ochs, 1986), ou seja, a habilidade de se expressar corretamente e de modo contextualizado, e de construir sentido a partir do que lhe é dito. Vimos com um exemplo dado acima que os Xikrin associam a aquisição da competência lingüística com a audição. Gostaria de recuperar alguns elementos observados no cotidiano que possam mostrar como essa competência é adquirida nas interações das crianças.

As habilidades expressivas das crianças são todas bastante encorajadas, fonte de comentários e orgulho. Os adultos gostam de ver crianças respondendo a um canto com passos de dança, e as mulheres gostam de colocar seus bebês próximos uns aos outros, encorajando sua interação. Tendo em vista o risco de perda do karon de um recém-nascido, as pessoas devem falar com ele quando está chorando, e essa necessidade de manter uma comunicação com ele pode ser entendida como um esforço de manter sua ligação com o mundo dos vivos e do social. Estando maiores e começando a falar, os adultos costumam forjar conversações com as crianças. Seguindo minha argumentação até aqui, recupero essa situação para demonstrar que essas conversas "forjadas" com as crianças não são simples fórmulas voltadas ao público infantil, e nem mesmo baby-talk. Assim os adultos não realizam, nesses casos (embora o façam freqüentemente), adaptações à habilidade comunicativa das crianças, tentando 
entender o que elas querem dizer e tornar sua fala compreensível, mas simulam uma situação de interação corriqueira entre as pessoas.

Essas conversas envolvem sempre, além da criança, no mínimo mais duas pessoas mais velhas, normalmente adultas. Elas versam sobre assuntos discutidos no cotidiano, como por exemplo atividades produtivas e relações entre as pessoas. Um dos adultos faz perguntas à criança, que são respondidas pelo outro como se fosse a endereçada, esperando-se que ela repita as respostas e dê continuidade à comunicação. Assim, utiliza-se termos tais como eles aparecem nos diálogos entre adultos, e versa-se sobre assuntos que não são eminentemente do universo infantil. Com freqüência, essas conversas são provocativas e jocosas, e as crianças são encorajadas e estimuladas a responder a essas provocações, normalmente com mais provocações. Simultaneamente, a criança aprende a se expressar e comunicar e atualiza relações sociais.

\section{A interação social e a construção pela criança de relações e de sentido}

Vejamos então como as abordagens antropológicas apresentadas no início deste artigo podem nos auxiliar a compreender o que há de específico no modo como os Xikrin concebem e vivenciam a infância. Se as crianças xikrin, como vimos, são caracterizadas pela maior intensidade de "vergonha", a qual vai sendo amenizada ao longo do ciclo de vida (o que significa que, correspondentemente, são os velhos os menos afetados por ela em suas interações), não têm, porém, seus movimentos tolhidos pela distância social, que restringe a interação entre determinadas categorias de pessoas, o que tem como conseqüência o fato de que elas, em termos práticos, podem entrar em todas as casas e atuar como mensageiras entre as casas e entre estas e o pátio, a Casa dos Homens (ngà).

A experiência das crianças xikrin nãoé, portanto, uma miniatura, ou uma mera imitação, do mundo adulto, mas, de fato, qualitativamente diversa deste. É a partir dela que elas podem mapear os contextos e as relações 
sociais que constituem a sociedade em que vivem, e nela atuar de um modo que não se confunde com o dos adultos. De fato, como vimos, em diversos momentos o que elas fazem pode parecer uma imitação do mundo adulto - como na caça a passarinhos dos meninos, que eram, ou deveriam ser, dados às irmãs, reais ou classificatórias, co-residentes ou não, para preparálos para eles, como ainda acontece com as frutas coletadas em suas excursões, ou como a pintura corporal realizada pelas meninas. No entanto, o que as crianças estão fazendo não é uma mera imitação do mundo adulto, mas uma constituição ativa de relações sociais que as acompanharão por toda a vida. Quando forem mães, essas meninas vão também se reunir para sessões de pintura corporal, tendo uma parceira fixa com quem se pintar (Vidal, 1992). Assim também, na distribuição de produtos da roça e de caça, a relação entre irmãos de sexo oposto permanece importante por toda a vida. Portanto, o que esses meninos estão fazendo, ao presentear suas irmãs com frutos colhidos em suas andanças, nessa idade mais comuns a eles que a elas, ou trazendo o produto de sua caça para que ela possa preparar para eles, não deve ser entendido como um ensaio das relações entre marido e mulher, mas como o início e a efetivação de uma relação de reciprocidade que poderá durar toda a vida.

A análise de Fisher (1991) sobre o sistema de parentesco xikrin demonstra como a construção ativa das relações sociais, que as análises de Gow da sociedade piro e de Strathern sobre a pessoa melanésia já haviam mostrado ser analiticamente rentável, é também bastante relevante entre os Xikrin. Fisher argumenta que as relações de parentesco são potencialidades que podem ou não ser postas em prática, e, portanto, atualizadas. Como Lea (1986) já havia indicado para os Metuktire, e como minha própria pesquisa confirma, esse autor mostra que os Xikrin fazem o cálculo de parentesco de acordo com as relações que seus pais estabelecem com a pessoa em questão, mas que esse cálculo "aritmético" não é suficiente para definir as relações efetivas entre as pessoas.

O modo como a geração mais velha classificava uns aos outros apenas fornece o quadro da rede de relações para aquele que chega [the 
newcomer]. Cada indivíduo torna-se socialmente definido no interior de um campo de relações através de trocas reais que ocorrem durante sua vida. (Fisher, 1991: 332, tradução minha).

As crianças xikrin, portanto, realizam, assim como os adultos, essa intersecção entre as relações sociais que recebem das gerações anteriores e aquelas que põem em prática e atualizam (ou, nos termos de Strathern, "ativam"). Vale dizer que essa construção pessoal de uma rede de relações tem continuidade ao longo da vida, e as relações podem ser revistas ${ }^{21}$. $\mathrm{O}$ importante, porém, é ter em mente que essa construção ativa a efetivação das relações sociais que têm início na infância, e que as crianças não somente aprendem e têm transmitidas relações com determinadas pessoas. Ou seja, mesmo no caso das interações regidas por parentesco, elas não apenas reproduzem o que recebem, mas, a partir desse quadro possível de relações, efetivam, recíproca e ativamente, algumas. Fazê-lo significa ter domínio sobre tratamentos apropriados para as diversas categorias de pessoas, porque só isso lhes permitirá ter a relação ativada de modo recíproco. Nessa atualização de relações potenciais, são estimuladas e mesmo auxiliadas pelos adultos, que as engendram em conversações que as posicionam ante um sem número de pessoas, e de modo contextualizado, mais ou menos jocoso ou respeitoso de acordo com os interlocutores. Se suas atividades não são divergentes das dos adultos, pelo simples motivo de que são informadas pelo mesmo aparato sociocultural, têm uma razão e um sentido construídos por elas próprias ${ }^{22}$.

Por fim, resta saber o que, para os Xikrin, define a singularidade da experiência infantil ${ }^{23}$, de um modo que possa nos fornecer uma concepção êmica da infância que vá além da pressuposição da incompletude da criança e de sua necessidade de socialização. Sugiro ser o desenvolvimento da faculdade de compreensão, ligada especialmente ao ouvido, o que torna a pessoa alguém que pode e deve compreender as normas sociais e atuar de modo correspondente a elas, capacitando-a, ainda, a dominar os conhecimentos tidos como relevantes, de um modo que exige sua participação ativa. Para aprender e compreender não basta desenvolver 
os órgãos de sentido e ter acesso às coisas do mundo. Cumpre demonstrar curiosidade e iniciativa (a exemplo da necessidade de pedir para que the seja ensinado algo), mas principalmente atenção e reflexão. Pois, como vimos, não basta ter a possibilidade de observar algo, ou ouvir algo, mas deve-se entendê-lo para que se efetive o aprendizado, e isso só é possível pela compreensão. Portanto, é esta, aliada a todos esses pressupostos, que se apresenta como o modo como os Xikrin concebem o desenvolvimento da criança em um ser social pleno. No entanto, sugeriria também que essa "plenitude" não deve ser contraposta a uma "incompletude" ${ }^{24}$, mas que os Xikrin concordariam, de bom grado, que as crianças se engajam legitimamente em interações sociais, e de um modo que é só seu. É assim que, olhos e ouvidos sempre atentos, vão conformando, em um processo contínuo do qual os adultos não estão isentos, sentidos para sua experiência.

\section{Notas}

1 Este artigo resulta da dissertação de mestrado que apresentei ao Departamento de Antropologia da USP (Cohn, 2000), e que contou com o apoio do CNPq, por meio de bolsa de mestrado, e da FAPESP, que financiou as pesquisas em campo por meio de Auxílio à Pesquisa individual e do Projeto Temático "Antropologia, História e Educação" (Processo 94/3492-9), desenvolvido no MARI - Grupo de Educação Indígena da USP -, instituições a que agradeço. Devo agradecer ainda a Lux Vidal, minha orientadora, e a Vanessa Lea e Beatriz Perrone-Moisés, que argüiram a dissertação oferecendo valiosas sugestões, assim como Aracy Lopes da Silva, que fez o mesmo no exame de qualificação, ao lado de Vanessa Lea; Márcio Silva foi também valioso, ao discutir comigo, junto ao Grupo de Estudos mantidos na USP, o debate em torno da abordagem da sociabilidade e socialidade. Desnecessário talvez mencionar que o título deste artigo remete às obras clássicas de Margaret Mead, incorporando porém uma diferença: de crescendo em Samoa a crescendo como um Xikrin.

2 Essa perspectiva reinou na antropologia por muito tempo, e pode ser vista, além do trabalho citado de Schaden, em Fernandes (1976), Schaden (1976), 


\section{Clarice Cohn. Crescendo como um Xikrin}

e Mayer (1973). Cf. Cohn (no prelo b) para uma discussão mais aprofundada sobre o modo como a antropologia vem trabalhando essa questão.

3 A análise de Strathern é sugestiva também de outro ponto, que diz respeito à discussão sobre os domínios e sua divisão entre feminino e masculino. Uma das possibilidades de interpretação da infância ente os grupos Jê seria a análise de sua passagem, diferenciada para homens e mulheres (mas válida, ao menos ritualmente, para ambos), da periferia ao centro, da natureza à cultura. O trabalho de Strathern permitiria que essa análise pudesse ser levada a cabo de um modo no qual centro e periferia, público e privado não fossem estabelecidos hierarquicamente, já que, como demonstrou para os melanésios, a esfera doméstica pode ser o espaço privilegiado de constituição da pessoa, no qual ela se engaja em interações sociais e na troca e reciprocidade (1988: 91) - o que, diga-se de passagem, viria a complementar o que exponho neste artigo.

4 Gianinni realizou sua pesquisa na aldeia xikrin do Cateté. No Bacajá, ninguém citou o kadjuo como elemento constitutivo da pessoa, e, quando perguntados diretamente, diziam não reconhecer a palavra.

5 Não sendo problematizada pelos Xikrin, a origem do karon não se constitui a partir de uma ligação direta com os pais, ao contrário do corpo, que é formado por esses, e com quem mantém uma relação de substância (como Da Matta [1976] demonstrou para os Apinayé) por toda a vida. Poderíamos retomar o argumento de Gow (1991: 155) para os Piro, que parece se encaixar bem ao caso xikrin, de que, se o corpo da criança vem do corpo dos pais, sua alma tem origem independente, constituindo-se portanto como um agente livre. Gow demonstra ainda como isso acarreta nos cuidados que os pais devem ter com os recém-nascidos, já que, mantendo com eles uma relação corpórea, não têm controle sobre sua alma; como a criança também ainda não o tem, ela poderia se retirar para acompanhar os pais e não conseguir mais retornar.

6 Beatriz Perrone-Moisés me chamou a atenção para esse ponto, a quem agradeço. Sobre a morte de crianças, ver Cohn (2000: 80-3).

7 Em que $a r y m=$ já, $b a=\mathrm{eu}, k u m a=$ saber (isso), de $k u m+$ mari e omunh $=$ ver. 
Revista de Antropologia, São Paulo, USP, 2000, v. 43 nº 2.

8 Em que akre $=$ mostrar e aren $=$ falar, contar. Fisher (1991: 250) traduz o termo akrê referindo-se à instrução formal.

9 Os meninos de cerca de 10 anos passam a morar no ngà, afastando-se assim da casa materna, e lá permanecendo até o casamento, quando vão morar na casa da esposa (cf. nota 10, abaixo).

10 Agradeço a Nádia Farage por ter me chamado a atenção para esse paralelo, ou seja, de que pular uma fase em um nível pode equivaler a pular em outro. Ressalte-se que esse constrangimento sobre a explicitação do conhecimento é em alguns casos menos rígido, e, por exemplo, um menino órfão de pai ou filho de mãe solteira, em sua condição excepcional, pode substituir a figura do pai confeccionando cestas e esteiras para sua mãe. Para uma discussão mais detalhada dessa questão, ver Cohn, (2000: 127-31).

11 A confecção das máscaras que dançam no ritual bô é um exemplo de algo a que as crianças são restringidas: elas não podem ver as máscaras serem feitas sob risco de enlouquecerem, ficarem aiban. Assim, as máscaras são confeccionadas no ngà, que é fechado com palha para que crianças e mulheres não as vejam, no único momento em que o que se passa na casa dos homens é recluso aos seus olhares. Lux Vidal (1977: 179) sugere que, tendo sido o bô aprendido pelos Kayapó dos Karajá (é uma versão do Aruanã), os Xikrin teriam incorporado também uma relação com o sobrenatural que não tem paralelo com seus outros rituais.

12 Cito aqui apenas algumas situações que auxiliam na argumentação do artigo. Para uma descrição mais detalhada do cotidiano das crianças e de sua participação em rituais, ver Cohn (2000: capítulo 3, e no prelo (a)).

13 A literatura sobre os Kayapó (Vidal, 1977; Turner ,1966 e 1979) enfatiza esse aspecto da sua organização social, lembrando que, se os homens são mais ligados à esfera pública e ao pátio e as mulheres à esfera privada e à periferia da aldeia, os meninos, ao contrário das meninas, devem passar da casa materna ao pátio, o que é realizado pela sua entrada na casa dos homens. Turner acrescenta ainda a essa análise a variável da residência uxorilocal, sugerindo que a passagem, quando jovens solteiros, pelo centro da aldeia seria um ponto intermediário entre a casa materna, onde nasceu, e a casa 


\section{Clarice Cohn. Crescendo como um Xikrin}

dos afins, onde passará a residir quando casado. Vemos aqui que a autonomia do menino ante a casa materna se realiza antes de sua formalização, que se dá no momento em que vai residir com outros rapazes no ngà.

14 O ninho de marimbondo, cuja derrubada é parte importante do ciclo ritual da iniciação dos rapazes, representa a aldeia inimiga (Vidal, 1977).

15 O atuk era uma casa construída a leste da aldeia, fora dos círculos das casas, onde os homens costumavam se reunir durante o dia e realizar suas atividades, como a confecção de artefatos, além de assar a carne de caça, que seria depois distribuída pelas casas; à noite, eles iriam para o centro da aldeia, onde não havia nenhuma construção, para realizar sua reunião (Vidal, 1977: 67-9). Hoje em dia, ele foi substituído pelo ngà, uma edificação central sem paredes, onde os homens se reúnem à noite mas também, quando estão na aldeia, de dia, em um modelo kayapó-gorotire.

16 Exceto no ritual $b \hat{o}$, no qual todas as meninas acompanham as máscaras, que cantam e dançam de casa em casa.

17 Sobre os nomes atribuídos aos recém-nascidos, veja Cohn (2000: 88-9) para os Xikrin do Bacajá; Vidal (1977), para os Xikrin do Cateté; Lea (1986: 1335) para os Kayapó-Makranoti; e Turner (1966: 171) para os Kayapó-Gorotire.

18 O mereremex pode ser feminino ou masculino; assim, no primeiro caso, os homens dançam e cantam durante a noite, e as mulheres acampam com as crianças no pátio; no segundo, a situação se inverte.

19 Entre os Xikrin, embora os papéis rituais sejam transmitidos a partir das mesmas categorias que entre os Timbira, não consolidam grupos, e a relação dos nomes com as prerrogativas rituais é diversa. Lopes da Silva (1986: 1545) propôs a análise dessa questão, seguindo Lévi-Strauss, sugerindo sua inclusão em um sistema de posições ou relações, alocando os Timbira no primeiro tipo, e os Kayapó, junto com os Xavante para a nominação masculina, no segundo. Como lembra ainda Lopes da Silva (: 162), as categorias de idade kayapó, que atuam nos rituais mas também no cotidiano, podem ser entendidas como o meio alternativo à filiação a grupos efetivada, entre os Timbira, pelos nomes. Lembre-se ainda que Lave (1979), argumentando a 
Revista de Antropologia, São Paulo, USP, 2000, v. 43 nº 2.

partir do caso Krikati, já havia demonstrado a atuação equivalente das categorias de idade e da nominação nas diversas variantes de organização social Jê, sugerindo que uma pode suplantar ou substituir a outra.

20 Isso pode sofrer algumas alterações, especialmente quando os jovens passam a ganhar espaço nos debates políticos ao se habilitarem privilegiadamente como mediadores perante o mundo externo quando este se constitui pela sociedade envolvente. Assim assisti a um longo discurso formal realizado por um jovem (mekranyre, pai de poucos filhos), no qual ele apresentava seu domínio do português e de contabilidade como uma habilidade política.

21 Como, por exemplo, após o casamento, em que várias das relações mantidas têm de ser remanejadas, e algumas pessoas, referidas até então por termos de consangüinidade, podem vir a ser reclassificadas como afins. Ressaltese nisso que não está em jogo aqui também simples cálculos aritméticos, mas que algumas relações permitem que as pessoas escolham as mudanças que vão ou não efetivar, reciprocamente, nelas.

22 A ênfase nesse artigo é na ativação de relações sociais, e no que possibilita a formação de significados, pelas crianças, do que testemunham e vivem. Os desenhos por elas realizados fornecem um meio privilegiado para verificar que significados são esses, o que explorei em Cohn (2000: 165-72).

23 Sugiro, em Cohn (2000: capítulo 5), que a pintura corporal se constitui em um meio de expressão da singularidade e do fim da infância; infelizmente, este tópico não pode ser abordado aqui, e remeto o leitor interessado a esse trabalho.

24 A análise do xamanismo entre os Xikrin do Cateté realizada por Giannini (1991a: 98-9) indica, inclusive, que a plenitude da humanidade não é alocada por eles na sociedade (ou seja, nem no centro, nem na periferia, nem em sua confluência), mas além, no céu, onde o xamã é iniciado e adquire a capacidade de intermediar os domínios constituintes do cosmo xikrin. 
Clarice Cohn. Crescendo como um Xikrin

\section{Bibliografia}

CAPUTO, V.

1995 "Anthropology's silent 'others': a consideration of some conceptual and methodological issues for the study of youth and children's cultures", in AMIT-TALAI, V.\& WULFF, H. (org.), Youth Cultures: a Cross-cultural Perspective, London, Routledge, pp. 19-42.

COHN, C.

2000 A criança indígena: a concepção Xikrin de infância e aprendizado, São Paulo, pp. 185, dissertação, USP.

no prelo (a) "A experiência da infância e o aprendizado entre os Xikrin", in LOPES DA SILVA, A. \& PEREIRA, A. N. (org.), Criança indígena. Ensaios antropológicos, São Paulo, Global/MARI-USP/FAPESP.

no prelo (b) "A criança, o aprendizado e a socialização na antropologia", in LOPES DA SILVA, A. \& PEREIRA, A. N. (org.), Criança indígena. Ensaios antropológicos, São Paulo, Global/MARI-USP/FAPESP.

DA MATTA, R.

1976 O mundo dividido. A estrutura social dos índios Apinayé, Petrópolis, Vozes.

FERNANDES, F.

1976 "Aspectos da educação na sociedade Tupinambá", in SCHADEN, E. (org.), Leituras de etnologia brasileira. São Paulo, Editora Nacional, pp. 63-86.

FISHER, W. H.

1991 Dualism and its Discontents: Social Organization and Village Fissioning among the Xikrin-Kayapo of Central Brazil, tese, pp. 509, Cornell University. 
Revista de Antropologia, São Paulo, USP, 2000, v. 43 nº 2.

GIANNINI, I. V.

1991a A ave resgatada: "a impossibilidade da leveza do ser", São Paulo, pp. 205, dissertação, USP.

1991b "Os domínios cósmicos: um dos aspectos da construção da categoria humana Kayapó-Xikrin”, Revista de Antropologia, vol. 34: 35-58.

GOW, P.

1991 Of Mixed Blood. Kinship and History in Peruvian Amazonia, Oxford, Claredon Press.

HOWELL, S.

1988 "From Child to Human: Chewong Concepts of Self", in JAHODA, G. \& LEWIS, I. M. (orgs.), Acquiring Culture: Cross Cultural Studies in Child Development, Londres/Nova Iorque/Sydney, Croom Helm, pp. 147-68.

LAVE, J.

1979 "Cycles and trends in Krikatí naming practices", in MAYBURY-LEWIS, D. (org.), Dialectical Societies: the Gê and Bororo of Central Brazil, Cambridge, Harvard University Press.

LEA, V.

1986 Nomes e Nekrets Kayapó: uma concepção de riqueza, Rio de Janeiro, pp. 563, tese, Museu Nacional/UFRJ.

LOPES DA SILVA, A.

1986 Nomes e amigos: da prática Xavante a uma reflexão sobre os Jê, São Paulo, FFLCH/USP, Série Antropologia, 6.

MAYER, P. (org.)

1973 Socialization: the Approach from Social Anthropology, Londres, Tavistock Publications. 
Clarice Cohn. Crescendo como um Xikrin

MELATTI, J. C.

1976 "Nominadores e genitores: um aspecto do dualismo krahó", in Schaden, E. (org.), Leituras de Etnologia Brasileira, São Paulo, Editora Nacional, pp . 139-48.

\section{OVERING, J.}

1988 "Personal Autonomy and the Domestication of the Self in Piaroa Society", in JAHODA, G. \& LEWIS, I. M. (orgs.), Acquiring Culture: Cross Cultural Studies in Child Development, Londres/Nova Iorque/Sidnei, Croom Helm, pp. 169-92.

\section{PELISSIER, C.}

1991 "The anthropology of teaching and learning", Annual Review of Anthropology, n. 20, pp. 75-95.

\section{SCHADEN,E.}

1945 "Educação e magia nas cerimônias de iniciação", Revista Brasileira de Estudos Pedagógicos, vol. III(8): 271-4.

1976 "Educação indígena", Problemas Brasileiros, ano XIV (152): 23-32.

SCHIEFFELIN, B. B. \& OCHS, E.

1986 “Language Socialization”, Annual Review of Anthropology, n. 15: 16391.

\section{SCHILDKROUT,E.}

1978 "Age and gender in Hausa Society: socio-economic roles of children in Urban Kano", in LA FONTAINE, J. S. (org.), Sex and Age as Principles of Social Differentiation, London/New York/San Francisco, Academic Press, pp. 109-37.

\section{SEEGER, A.}

1980 "O significado dos ornamentos corporais", in Os índios e nós, Rio de Janeiro, Campus, pp. 43-57. 
Revista de Antropologia, São Paulo, USP, 2000, v. $43 n^{\circ} 2$.

\section{STRATHERN, M.}

1988 The Gender of the Gift, Berkeley/Los Angeles/Londres, University of California Press.

\section{TOREN,C.}

1990 Making Sense of Hierarchy: Cognition as Social Process in Fiji, Londres, Athlone Press.

1999 Mind, Materiality and History. Explorations in Fijian Ethnography, Londres/Nova Iorque, Routledge.

TURNER, T.

1966 Social Structure and Political Organization among the Northern Kayapo, Cambridge, MA, pp. 535, tese, Harvard University.

1979 "Kinship, household, and community structure among the Kayapó", in MAYBURY-LEWIS, D. Dialectical Societies: the Gê and Bororo of Central Brazil, Cambridge, Harvard University Press, pp. 179-214.

1981 "The Social Skin”, in CHEFAS, J. \& LEWIN, R. (org.), Not Work Alone. Survey of activities superfluous to survival, London, Temple Smith, pp. 112-40.

1995 "Social Body and Embodied Subject: Bodiliness, Subjectivity, and Sociality among the Kayapo", Cultural Anthropology, vol. 10(2): 14370.

VIDAL, L.

1977 Morte e vida de uma sociedade indígena brasileira, São Paulo, Hucitec.

1992 "A pintura corporal e a arte gráfica entre os Kayapó-Xikrin do Cateté", in VIDAL, L. (org.), Grafismo indígena, São Paulo, Nobel/EDUSP/ FAPESP, pp. 143-89. 


\section{Clarice Cohn. Crescendo como um Xikrin}

ABSTRACT: The development of children among the Xikrin, an indigenous people of Northern Brazil, is examined through the study of their own conceptions of childhood and growing up, along with an analysis that focuses on the way children actively enact themselves on this process. Thus, the paper aims to contribute to the ongoing effort towards recovering those anthropological analyses of childhood among other societies which focus on conceptions of the Self and of the active participation of the child in its insertion in social life, refusing a view of socialisation as the way to impinge on "immature people", which imitate adult life, proper values and behaviours.

KEY-WORDS: anthropology of childhood, socialisation, anthropology of learning, knowledge transmission.

Recebido em julho de 2000 